\title{
Advances in Utilizing Cyanobacteria for Hydrogen Production
}

\author{
Galyna Kufryk \\ College of Arts and Sciences, Grand Canyon University, Phoenix, USA \\ Email: Galyna.Kufryk@gcu.edu
}

Received July 17, 2013; revised July 20, 2013; accepted July 23, 2013

Copyright (C) 2013 Galyna Kufryk. This is an open access article distributed under the Creative Commons Attribution License, which permits unrestricted use, distribution, and reproduction in any medium, provided the original work is properly cited.

\begin{abstract}
Cyanobacteria are photoautotrophic prokaryotes with a remarkable metabolic flexibility. Many species of cyanobacteria produce hydrogen, and the efficiency of this process can be improved by genetic engineering. Isolated photosynthetic complexes of cyanobacteria that are capable of light absorption and charge separation can be utilized in hydrogen-producing devices that are driven by solar energy. As photosynthetic microorganisms, cyanobacteria present a unique opportunity for creating low cost systems for hydrogen production in vivo and in vitro. This review is focused on recent advances in cyanobacterial hydrogen research.
\end{abstract}

Keywords: Cyanobacteria; Hydrogen; Bioengineering; Photosynthesis; Electron Transport

\section{Introduction}

Since their appearance in Precambrian times [1], cyanobacteria developed into a very diverse group that occupied a large variety of ecological niches. This remarkable hardiness of cyanobacteria is largely due to the unique metabolic flexibility that allows them to use a wide range of carbon and energy sources. Cyanobacteria were the first organisms to develop photosynthetic machinery that utilized energy of sunlight to drive the reaction of water oxidation that produced molecular oxygen. As prokaryotic photoautotrophs, they have very modest nutrient needs, a short life cycle and many strains can be cultivated on a large scale very inexpensively. Copious amounts of genetic information are available for cyanobacteria (http://genome.microbedb.jp/cyanobase/) and some cyanobacterial species are transformable. This makes cyanobacteria suitable for bioengineering. On the other hand, metabolic flexibility of cyanobacteria and a growing body of metabolomic information are helpful in assessing their productive potential [2].

Hydrogen has the highest mass energy density of any fuel; when utilized, it does not generate carbon dioxide and other pollutants; it can be produced by living organisms. This makes hydrogen an attractive option in our quest for renewable, environmentally acceptable alternatives to fossil fuels [3]. Biological production of hydrogen by cyanobacteria can be very economical considering low energy requirements and low initial investment costs. In view of this, current research efforts are focused on bioengineering cyanobacterial strains with high levels of hydrogen production. Another growing area of interest is a design of light-driven electrochemical systems for hydrogen production that will utilize components of cyanobacterial photosynthetic machinery. This paper is focused on current advances in applying cyanobacteria for hydrogen production.

\section{Biochemical Pathways for Hydrogen Production in Cyanobacterial Cells}

More than forty strains of cyanobacteria that belong to fourteen genera are naturally capable of hydrogen production [4] albeit the production levels are naturally low (Table 1, wild types). Environmental factors such as light, temperature, salinity, availability of micronutrients, concentration of molecular oxygen, source of carbon and nitrogen for cyanobacterial culture affect hydrogen production in vivo and have been studied extensively [4].

There are three pathways of hydrogen production in cyanobacteria. In one of them, molecular hydrogen is produced by hydrogenase from the electrons that are supplied by the reduced NADPH (Figure 1). NADPH is formed as a result of light-driven electron transport from water via photosystem II (PS II) through photosystem I (PS I), ferredoxin (Fd) to ferredoxin: $\mathrm{NADP}^{+}$oxidoreductase (FNR). Since formation of NADPH is driven by light absorption and electron transport, this pathway of 
Table 1. Effect of genetic modifications on hydrogen production by cyanobacteria.

\begin{tabular}{|c|c|c|c|}
\hline Strain & Mutation & Hydrogen evolution, $\mu \mathrm{mol} /\left(\mathrm{mg} \mathrm{Chl}^{*} \times \mathrm{h}\right)$ & Reference \\
\hline \multirow{3}{*}{$\begin{array}{l}\text { Synechocystis sp. } \\
\text { PCC } 6803\end{array}$} & wild type & 1.2 & \multirow{2}{*}[21]{} \\
\hline & $\Delta n d h B$ & 6 & \\
\hline & psbAII promoter: hoxE & 4 & {$[22]$} \\
\hline \multirow{2}{*}{$\begin{array}{l}\text { Synechococcus elongatus } \\
\text { sp. } 7942\end{array}$} & wild type & 0 & \multirow{2}{*}[23]{} \\
\hline & hyd A from Clostridium acetobutylicum & 2.8 & \\
\hline \multirow{2}{*}{$\begin{array}{l}\text { Nostoc sp. } \\
\text { PCC } 7422\end{array}$} & wild type & 33 & \multirow{2}{*}[35]{} \\
\hline & $\Delta$ hupL & 100 & \\
\hline \multirow{2}{*}{$\begin{array}{l}\text { Anabaena variabilis } \\
\text { ATCC } 29413\end{array}$} & wild type & 39.4 & \multirow{2}{*}{ [19] } \\
\hline & $\Delta$ hupSL & 137 & \\
\hline \multirow{2}{*}{$\begin{array}{l}\text { Anabaena (Nostoc) sp. } \\
\text { PCC } 7120\end{array}$} & wild type & 2.6 & \multirow{2}{*}{ [33] } \\
\hline & $\Delta$ hupL & 10.4 & \\
\hline \multirow{2}{*}{$\begin{array}{l}\text { Anabaena siamensis } \\
\text { TISTR } 8012\end{array}$} & wild type & 8.0 & \multirow{2}{*}[34]{} \\
\hline & $\Delta$ hups & 29.7 & \\
\hline
\end{tabular}

hydrogen production is also light-dependent. It is coupled to the photosynthetic water oxidation that generates molecular oxygen and thus usually is not highly active as hydrogenases are inhibited by oxygen.

Another pathway of hydrogen production takes electrons from NADPH that is generated in the process of degradation of polysaccharides or lipids that were accumulated and stored in cyanobacterial cells [5]. In the process of NADPH oxidation, electrons are shuttled to the plastoquinone (PQ) pool and subsequently used for hydrogen biosynthesis. This pathway depends on catabolism of stored polysaccharides and is not directly lightdependent. However, since monomers of these polysacharides are produced in the dark reactions of photosynthesis, ultimately their synthesis is light-driven. This pathway of hydrogen production is most common in cyanobacteria and allows for a temporal separation of anaerobic hydrogen production and light-driven water oxidation and oxygen evolution [6].

The third pathway for hydrogen production is concomitant with cyanobacterial fixation of molecular nitrogen by nitrogenase. Nitrogenase-dependent production of molecular hydrogen occurs primarily in anaerobic environment that is created inside the nitrogen-fixing cyanobacterial cells. The source of electrons for nitrogen fixation could be light-driven water oxidation and photosynthetic electron transport or enzymatic degradation of stored polysaccharides. Therefore, in terms of the origin of electrons and protons this pathway combines the first two. However, it is more energy demanding, compared to them. Another drawback of this pathway is that the generated hydrogen quite often is oxidized by the uptake hydrogenase and the electrons are transferred back to the nitrogenase or to the PQ pool [6].

\section{Cyanobacterial Enzymes as Targets for Bioengineering}

Cyanobacterial hydrogen production depends on the presence of at least two types of hydrogenases: bidirectional $[\mathrm{NiFe}]$ hydrogenase and uptake [NiFe] hydrogenase [7]. Nitrogen-fixing strains that produce molecular hydrogen concomitantly with fixation of molecular nitrogen, contain [MoFe] nitrogenase, although in some strains vanadium atom replaces molybdenum atom in the prosthetic group [8].

\subsection{Bidirectional Hydrogenase}

Bidirectional hydrogenases catalyze the following reaction:

$$
2 \mathrm{H}^{+}+2 \mathrm{e}^{-} \leftrightarrow \mathrm{H}_{2}
$$

For the reaction of production of molecular hydrogen, these enzymes use NADPH as electron donor. Bidirectional hydrogenase of cyanobacteria has pentameric structure and is located in the cytoplasmic membrane. In Synechocystis sp. PCC 6803 all five genes that encode hydrogenase subunits (hoxEFUYH) are localized in one cluster and co-expressed. Maturation of bidirectional hydrogenase requires several auxiliary Hyp proteins [9]. It is possible to increase hydrogen production in Synechocystis sp. PCC 6803 (Table 1) by overexpression of 


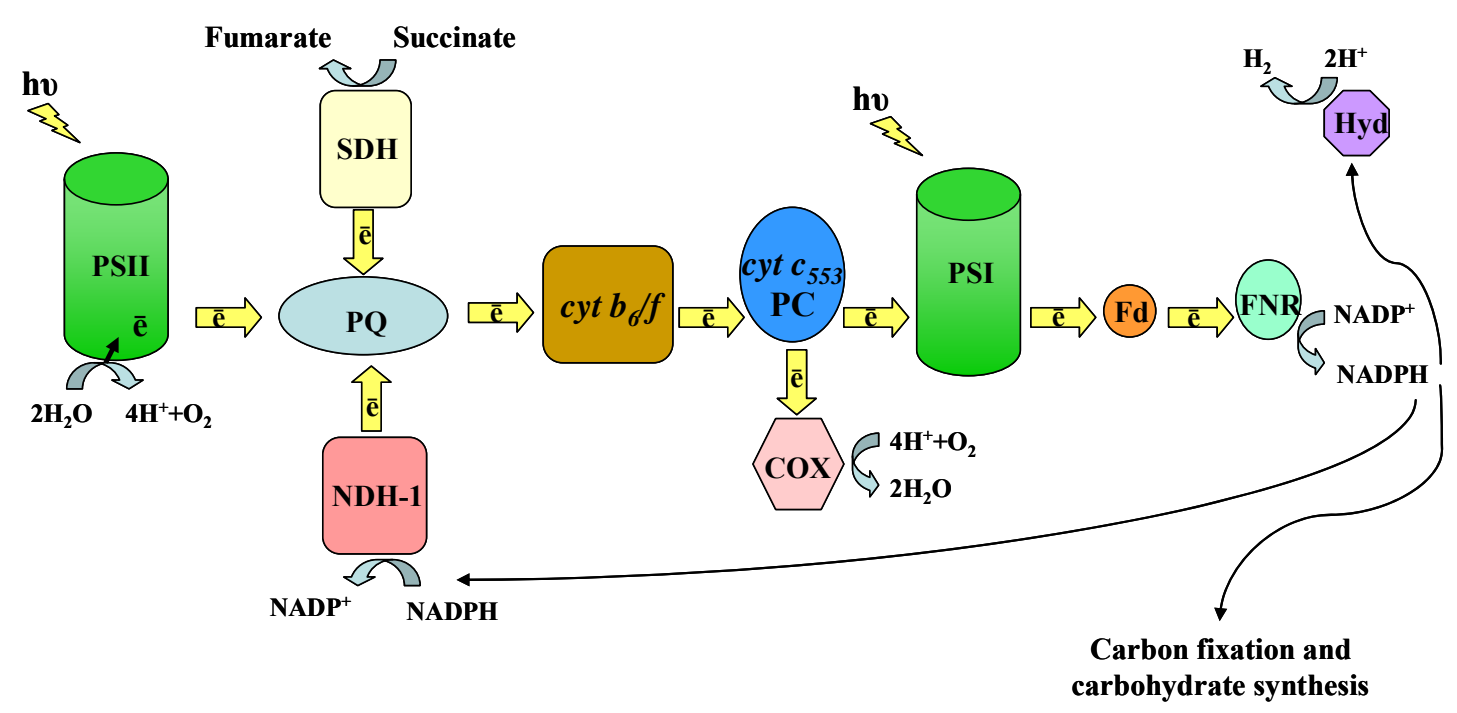

Figure 1. Main components of photosynthetic and respiratory electron transport system in cyanobacteria. PSII-photosystem II, PQ-plastoquinone pool, cyt-cytochrome, PC-plastocyanin, PSI-photosystem I, Fd-ferredoxin, FNR-ferredoxin: NADP+ oxidoreductase, Hyd—hydrogenase, SDH—succinate dehydrogenase, NDH-1—NADPH: quinone oxidoreductase, COX - cytochrome oxidase.

bidirectional hydrogenase [10] and deletion of NDH-1 respiratory complex [11].

Catalytic activity of this enzyme is associated with HoxH and HoxY proteins whereas the remaining three proteins form a diaphorase unit [12]. While hox genes are constitutively expressed in the presence of oxygen, hydrogen is produced until oxygen is accumulated during photosynthetic reactions in the quantities that inhibit bidirectional hydrogenase [13]. This process is reversible: hydrogen production by the existing hydrogenase resumes once oxygen is removed or consumed by respiration. Reactivation of enzyme can be sped up by NADH or NADPH at catalytic concentrations [11]. Targeted mutagenesis of cyanobacterial hydrogenases is currently explored to create less oxygen-sensitive enzymes. Alternatively, inhibition of oxygen evolution by PS II can be induced to prevent oxygen poisoning of hydrogenase in vivo.

Cellular localization and physiological significance of bidirectional hydrogenase is a matter of much debate. This enzyme was found in all non-nitrogen-fixing cyanobacterial strains but some nitrogen-fixing cyanobacteria lack it [14]. Therefore, it does not play an indispensable role in cell metabolism overall. It was shown to be present in cytoplasm of cyanobacterial cells as well as loosely associated with cytoplasmic and thylakoid membranes $[15,16]$. Bidirectional hydrogenase may serve as a valve for low potential electrons that are generated in light reactions of photosynthesis [13]; it may facilitate oxidation of molecular hydrogen in periplasmic space and shuttle electrons to the respiratory electron transport chain [12]; it may help re-oxidize excessive NADH formed during glycolysis [17]. The fact that amino acid sequence of this enzyme bears conserved regions that are similar to respiratory complex I subunits [15] may indicate that bidirectional hydrogenase might function as a NADPH: plastoquinone oxidoreductase. It is possible that different cyanobacterial strains use this enzyme in different ways or not at all.

\subsection{Uptake Hydrogenase}

Uptake hydrogenase is found predominantly in nitrogen-fixing cyanobacterial strains [18]. Based on the absence of $\mathrm{N}$-terminal signal sequence in the primary structure of cyanobacterial uptake hydrogenase, this enzyme is believed to be associated with the cytoplasmic side of cytoplasmic or thylakoid membranes [6,19]. This protein consists of HupL polypeptide that binds molecular hydrogen, and HupS polypeptide that plays a role in hydrogen oxidation. Uptake hydrogenase is less sensitive to molecular oxygen, compared to bidirectional hydrogenase [20].

This enzyme helps with oxidation and utilization of molecular hydrogen that is generated by nitrogenase in nitrogen-fixing cells. Therefore, enzymatic activity of uptake hydrogenase is counteractive to the production of molecular hydrogen by nitrogen-fixing cyanobacteria. Genetic manipulations that reduce or eliminate activity of uptake hydrogenase (Table 1) increase hydrogen production by these strains [21-25].

Alternatively, strains that naturally lack uptake hydrogenase (such as Synechocystis sp. PCC 6803) are being explored for the purpose of hydrogen production. While taking this approach, it is important to evaluate the over- 
all hydrogen yield as the lack of uptake hydrogenase a priori does not result in higher hydrogen production by cyanobacteria. For instance, hydrogenase-deficient Cyanothece 7425 produces less hydrogen compared to a hydrogenase-containing Cyanothece 51142 [26].

\subsection{Cyanobacterial Nitrogenase}

Nitrogen-fixing strains of cyanobacteria contain nitrogenase that is a catalyst of the following reaction:

$$
\begin{aligned}
& \mathrm{N}_{2}+16 \mathrm{H}_{2} \mathrm{O}+16 \mathrm{ATP}+10 \mathrm{H}^{+}+8 \mathrm{e}^{-} \\
& \rightarrow 2 \mathrm{NH}_{4}^{+}+\mathrm{H}_{2}+16 \mathrm{ADP}+16 \mathrm{Pi}
\end{aligned}
$$

Due to the fact that reactions that are catalyzed by nitrogenase are practically irreversible, significant quantities of the final products can be accumulated.

The most common form of cyanobacterial nitrogenase consists of iron-containing dinitrogenase reductase (Fe protein) and dinitrogenase (FeMo protein). The Fe protein has a single $[4 \mathrm{Fe}-4 \mathrm{~S}]$ cluster and it carries electrons from reduced $\mathrm{Fd}$ or flavodoxin to the FeMo protein. The FeMo protein has two unique metal clusters, the [8Fe-7S] P-cluster and the [1Mo-7Fe-9S-1X-homocitrate] FeMo cofactor; the latter is the active site of nitrogenase. Biological activity of this enzyme produces molecular hydrogen as a byproduct of nitrogen reduction using ATP. In the absence of molecular nitrogen, this enzyme can still produce hydrogen albeit less ATP is needed for this reaction:

$$
4 \mathrm{ATP}+2 \mathrm{H}^{+}+2 \mathrm{e}^{-} \rightarrow \mathrm{H}_{2}+4 \mathrm{ADP}+4 \mathrm{Pi}
$$

This phenomenon can be used to redirect electron flow from nitrogen fixation to hydrogen production. Traditionally, a switch from nitrogen fixation to hydrogen production was made by replacing molecular nitrogen with argon in the gas mixture to which cyanobacteria were exposed. Recently, genetic modifications in homocitrate synthase (homocitrate is a part of FeMo cofactor of nitrogenase) were attempted for this purpose and showed improvement in hydrogen yield in $\Delta h u p L$ strain of Nostoc sp. PCC 7120 [27]. Mutations of amino acids within $5 \AA$ of the FeMo cofactor in the active site of nitrogenase resulted in strains that were capable of aerobic hydrogen production in the presence of molecular nitrogen at the levels comparable to hydrogen production in argon atmosphere [28]. This is a promising development in bioengineering of hydrogen-producing filamentous strains.

Similarly to cyanobacterial hydrogenases, nitrogenase is extremely sensitive to oxygen. In nature this problem is circumvented by either spatial or temporal separation of photosynthetic oxygen production and nitrogen fixation.

Spatial separation is achieved by filamentous cyano- bacteria that form heterocyst, a specialized type of cells that harbor nitrogenase. Typical filamentous nitrogenfixing cyanobacterium contains 5\% - 10\% heterocysts [29]. Thick cell wall prevents quick penetration of external $\mathrm{CO}_{2}$ into heterocysts; lack of PS II does not allow for internal production of molecular oxygen whereas a high respiration rate keeps oxygen concentration very low and produces much needed ATP for nitrogenase.

Since nitrogenase also produces molecular hydrogen, frequency of heterocyst formation in filamentous cyanobacteria can be a factor that increases hydrogen production [30,31]. To this end, the highest frequency of heterocyst formation in free-living cyanobacteria $(>30 \%$ of the total cells) was achieved by transposon mutagenesis in Nostoc punctiforme [32].

Besides increase in heterocyst formation in filamentous cyanobacteria, another advantageous step would be a deletion of uptake hydrogenase that quickly consumes molecular hydrogen as described above, as well as a quick removal of the final products of the nitrogenase reaction from the cyanobacterial growth medium [33].

Non-filamentous nitrogen-fixing cyanobacteria utilize temporal separation of nitrogen fixation and oxygen evolution. Oxygenic photosynthetic processes occur during illumination of cyanobacterial culture whereas nitrogen fixation occurs during growth in dark.

Unlike bidirectional hydrogenase, cyanobacterial nitrogenase is not merely inactivated under oxygenic conditions but undergoes enzymatic degradation so that the cells lack this protein while grown at light [34,35]. From the standpoint of hydrogen production, one of the most promising non-filamentous nitrogen-fixing cyanobacteria is Cyanothece 51142. This strain can produce hydrogen at rates as high as $465 \mu \mathrm{mol} /(\mathrm{mg}$ chlorophyll $\times \mathrm{h})$ in the presence of glycerol as a carbon source [36]. At this time, there are no genetic tools developed for this organism but with their advent hydrogen yield can be further improved. As a part of cellular metabolism, hydrogen production is affected by other biochemical processes. Currently a complete metabolic model of Cyanothece 51142 is available to assess the overall theoretical capacity of this organism for hydrogen production [2].

Hydrogen-evolving properties of halotolerant cyanobacteria are also being explored; of those, Aphanothece halophytica demonstrates a good potential with hydrogen production rate up to $14 \mu \mathrm{mol} /(\mathrm{mg}$ chlorophyll $\times \mathrm{h})$ [37].

\section{Other Means of Improving Hydrogen Production in Vivo}

\subsection{Expression of Heterologous Hydrogenase}

One of the problems for in vivo hydrogen production stems from a low specific activity of the innate cyanobacterial $[\mathrm{NiFe}]$ hydrogenases that use NADPH rather 
than energetically more favorable $\mathrm{Fd}$ as the preferred electron donor (Figure 1). Therefore, heterologous expression of highly active enzymes from other organisms is explored. Recent studies show that expression of [FeFe] hydrogenase (HydA) from Clostridium acetobutylicum in Synechococcus elongatus sp. 7942 resulted in over 500fold increase of hydrogen yield under anaerobic conditions in vitro, and an average hydrogen yield of 2.8 $\mu \mathrm{mol} /(\mathrm{mg}$ chlorophyll $\times \mathrm{h})$ in vivo [38]. Interestingly, this mutant was capable of limited chemoautotrophic growth utilizing molecular hydrogen as energy source.

Oxygen sensitivity of cyanobacterial hydrogenases is a serious obstacle for photolytic hydrogen production. It can be circumvented by introducing oxygen-tolerant hydrogenases. [NiFe] hydrogenase from Alteromonas macleodii Deep ecotype that is tolerant to $1 \%-3 \%$ oxygen was successfully expressed in Synechococcus elongatus sp. 7942. Heterologously expressed enzyme was functional in vitro [39] but no data regarding hydrogen production by the mutant strain in vivo are reported at this time.

\subsection{Genetic Engineering of Biochemical Pathways}

Reducing equivalents that are used by hydrogenase are also needed for other metabolic processes in cyanobacterial cell (Figure 1). In view of this, a comprehensive evaluation of metabolic fluxes in the cell provides information about metabolic potential of the species and the ways to direct more substrate toward hydrogen production [2].

Increase in hydrogen production can be achieved by reducing or eliminating competing biochemical pathways. For instance, inactivation of quinol oxidase (COX) or nitrate reductase resulted in the increase of hydrogen production in vivo by Synechocystis sp. PCC 6803 [40].

Concentration of substrate, NADPH and/or $\mathrm{H}^{+}$has been shown to limit in vivo hydrogen production by cyanobacteria in certain cases [41]. Genetic manipulations that lead to the increase of the NADPH/NADP ${ }^{+}$ratio also cause elevation of hydrogen production by an NADPHdependent, bidirectional [NiFe] hydrogenase in Synechococcus sp. strain PCC 7002 [17,42].

Expression of heterologous hydrogenases and modification of biochemical pathways in cyanobacterial cell toward hydrogen production can be useful tools in bioengineering highly efficient hydrogen-producing strains.

\section{Cells and Molecular Complexes of Cyanobacteria in Bio-Inspired Systems for Hydrogen Production}

Because of the complexity of biochemical pathways and regulatory mechanisms in cyanobacterial cells that have to be tuned up to achieve the high levels of hydrogen production in vivo, the alternative options were proposed that utilized cyanobacteria or the isolated components of their cells.

Hydrogen can be generated by bio-photoelectrolytic devices. Recently, a system with anodic chamber containing whole cells of Synechocystis sp. PCC 6803 was tested [43]. Using $\left(\mathrm{Fe}[\mathrm{CN}]_{6}\right)^{3-}$ as the electron mediator and platinum cathode, this device was able to produce $0.68 \mathrm{mmol} \mathrm{H}_{2} /(\mathrm{mol}$ chlorophyll $\times \mathrm{s})$ while $1.4 \mathrm{~V}$ biaspotential was applied. It should be noted that in this case a genetic knockout of cyanobacterial terminal oxidases that are deemed as alternative electron sinks and reduce electron flow toward FNR (Figure 1) had no effect on hydrogen-producing capacity.

Components of cyanobacterial photosynthetic and hydrogen-producing machinery are among the best studied protein complexes that gave us insight into the processes of energy conversion and utilization. They laid the ground for numerous semi-artificial devices for hydrogen production. Their design is based on coupling a photosensitizer (PS I or PS II complexes) and a hydrogen-producing catalyst (noble metal or hydrogenase) in a way that is conducive to the process of light-driven electron transfer from the photosensitizer to the hydrogen-producing part of the system.

\subsection{Photosystem I-Based Devices}

Light-driven hydrogen production can be generated by coupling cyanobacterial PS I with noble metals such as $\mathrm{Au}$ or Pt. They can be utilized in a two-electrode electrochemical system or noble metals can be directly deposited onto PS I complexes.

To achieve high photocurrent, PS I electrode should have an orderly arrangement of PS I complexes and a good communication between PS I and the electrode surface. When Os-based redox polymer hydrogel was used to trap PS I on the electrode surface, the highest currents were produced [44]. Upon illumination such electrode was maintaining a catalytic photocurrent with densities of up to $29 \mathrm{~mA} / \mathrm{cm}^{2}$ at a light intensity of 1.8 $\mathrm{mW} / \mathrm{cm}^{2}$. Besides high photocurrent, the advantage of this system was that a hydrogel served simultaneously as immobilization matrix and as electron donor for PS I.

In metal-PS I particles, a close connection between two components can be achieved by the reductive deposition of metal on PS I reaction center or covalent attachment. Detailed protocol for molecular wiring of PS I was developed [45-47]. Such systems require a sacrificial electron donor to operate. Ascorbate, cyt $c$ and phenazine methosulfate are among the most frequently used electron donors of PS I.

Efficiency PS I-Pt system was demonstrated on platinized nanoparticles of PS I from Thermosynechococcus 
elongatus that were capable of maintaining hydrogen production up to $5.5 \mu \mathrm{mol} /(\mathrm{mg}$ chlorophyll $\times \mathrm{h})$ [48]. Electron transport from sodium ascorbate via PS I to cytochrome $c_{6}$ was driving hydrogen formation on platinum. Since this system used PS I from thermophilic cyanobacterium, hydrogen production was observed at temperatures up to $55^{\circ} \mathrm{C}$, and the device could be used intermittently for over 85 days.

Alternatively, PS I can be fused or wired to hydrogenase. For instance, product of fusion of membranebound $[\mathrm{NiFe}]$ hydrogenase from the $\beta$-proteobacterium Ralstonia eutropha H16 and PsaE subunit of PS I of the cyanobacterium Thermosynechococcus elongatus was capable of spontaneous association with PsaE-free PS I. The resulting hydrogenase-PS I complex was fully functional, maintained light-driven hydrogen production at a rate of $0.58 \mu \mathrm{mol} /(\mathrm{mg}$ chlorophyll $\times \mathrm{h})$, and was able to bind native electron acceptor, Fd [49]. Bonding of a fused protein to an electrode caused a substantial increase in hydrogen production but this device was not very stable [50].

A very interesting result was obtained when PS I was connected by alkane dithiol molecular wire to C97G mutant of HydA, a [FeFe] hydrogenase from Clostridium acetobutylicum. The system was capable of producing up to $30.3 \mu \mathrm{mol} \mathrm{H}_{2} /(\mathrm{mg}$ chlorophyll $\times \mathrm{h})$ and was stable for at least 64 days [51]. This is the highest level of hydrogen production in the cyanobacterial PS I-based system to date.

\subsection{Photosystem II-Based Devices}

PS II can be coupled with hydrogenase or platinum to create a light-driven system for hydrogen production. Commonly PS II is deposited on electrode. Several solutions were proposed to achieve an orderly deposition of PS II complexes on electrode surface and high photocurrent that is generated by the PS II electrode.

One of such devices used wild type and recombinant PS II from thermophilic cyanobacteria (Synechococcus bigranulatus and Synechococcus elongatus, respectively) deposited onto a gold electrode that was chemically modified to either bind his-tagged PS II particles or to provide a conductive layer of poly-mercapto- $p$-benzoquinone that facilitates electron transport from the PS II to the electrode. These electrodes allowed for a controlled formation of a PS II monolayer on their surface and provided a high density of photocurrent but were not stable (a half-life of about 1 - 3 hours due to the PS II degradation under experimental conditions [52,53].

A similar approach was used to create a PS II electrode using his-tagged PS II from Thermosynechococcus elongatus that was attached to a gold electrode modified with thiolates and bearing terminal $\mathrm{Ni}(\mathrm{II})$-nitriloacetate groups [54]. A high density of recombinant protein was deposited onto the electrode $\left(0.29 \mathrm{pmol} / \mathrm{cm}^{2}\right)$. When used with 2, 6 dichloro- $p$-benzoquinone as electron acceptor and an applied oxidation potential of $0.3 \mathrm{~V}$, this electrode produced a photocurrent density of up to $14 \mu \mathrm{A} / \mathrm{cm}^{2}$, and demonstrated an action spectrum similar to that of PS II. The latter proved that the photocurrent did originate from the PS II complexes deposited onto the electrode. The authors did not report the working lifetime of this electrode but since the material of electrode and principle of PS II deposition on the surface are the same as in earlier experiments $[52,53]$, the expected half-life of the device should be around 1 to 3 hours.

PS II can also be deposited on electrode using Osbased crosslinked hydrogels [55]. Such electrode developed a photocurrent density of up to $18 \mu \mathrm{A} / \mathrm{cm}^{2}$ under illumination, and was the most stable of all previous designs (half-life of $245 \mathrm{~min}$ ).

The limited working lifetime of the electrode remains a major obstacle in creating a reliable system for electrochemical production of hydrogen using the water-oxidizing capacity of PS II. Another important aspect of the problem is the choice of material for the electrode that would not include precious or rare materials.

Hydrogen-producing systems that are based on cyanobacterial protein complexes provide a valuable testing ground for the future development of light-driven biomimetic devices.

\section{Conclusion}

Cyanobacteria provide unique opportunities for studying biological production of hydrogen. Biological diversity of cyanobacteria is a fertile ground for exploring hydrogen-producing varieties. Our current knowledge of cyanobacterial biochemistry and genetics is instrumental in bioengineering strains with improved hydrogen yield. Isolated photosystems of cyanobacteria are tested to create light-driven electrochemical devices that produce hydrogen. As sunlight remains the most abundant and reliable source of energy, our insight into light conversion and hydrogen production in cyanobacteria is essential for creating renewable alternatives to fossil fuels.

\section{REFERENCES}

[1] J. W. Schopf, "The Paleobiological Record of Photosynthesis," Photosynthesis Research, Vol. 107, No. 1, 2011, pp. 87-101. http://dx.doi.org/10.1007/s11120-010-9577-1

[2] R. Saha, A. T. Verseput, B. M. Berla, T. J. Mueller, H. B. Pakrasi and C. D. Maranas, "Reconstruction and Comparison of the Metabolic Potential of Cyanobacteria Cyanothece sp. ATCC 51142 and Synechocystis sp. PCC 6803," PLOS ONE, Vol. 7, No. 10, 2012, Article ID: e48285. http://dx.doi.org/10.1371/journal.pone.0048285

[3] P. P. Edwards, V. L. Kuznetsov and W. I. F. David, "Hydrogen Energy," Philosophical Transactions of the Royal 
Society, Vol. 365, No. 1853, 2007, pp. 1043-1056. http://dx.doi.org/10.1098/rsta.2006.1965

[4] D. Dutta, D. De, S. Chaudhuri and S. K. Bhattacharya, "Hydrogen Production by Cyanobacteria," Microbial Cell Factories, Vol. 4, 2005, p. 36. http://dx.doi.org/10.1186/1475-2859-4-36

[5] J. Mathews and G. Wang, "Metabolic Pathway Engineering for Enhanced Hydrogen Production," International Journal of Hydrogen Energy, Vol. 34, No. 17, 2009, pp. 7404-7416.

http://dx.doi.org/10.1016/j.ijhydene.2009.05.078

[6] J. Appel and R. Schulz, "Hydrogen Metabolism in Organisms with Oxygenic Photosynthesis: Hydrogenases as Important Regulatory Devices for a Proper Redox Poising?" Journal of Photochemistry and Photobiology, Vol. 47, No. 1, 1998, pp.1-11. http://dx.doi.org/10.1016/S1011-1344(98)00179-1

[7] M. Ludwig, R. Schulz-Friedrich and J. Appel, "Occurrence of Hydrogenases in Cyanobacteria and Anoxygenic Photosynthetic Bacteria: Implications for the Phylogenetic Origin of Cyanobacterial and Algal Hydrogenases," Journal of Molecular Evolution, Vol. 63, No. 6, 2006, pp. 758-768. http://dx.doi.org/10.1007/s00239-006-0001-6

[8] S. V. Shestakov and L. E. Mikheeva, "Genetic Control of Hydrogen Metabolism in Cyanobacteria", Russian Journal of Genetics, Vol. 42, No. 11, 2006, pp. 1272-1284. http://dx.doi.org/10.1134/S1022795406110093

[9] R. Wünschiers, M. Batur and P. Lindblad, "Presence and Expression of Hydrogenase Specific C-Terminal Endopeptidases in Cyanobacteria," BMC Microbiology, Vol. 3, 2003, p. 8. http://dx.doi.org/10.1186/1471-2180-3-8

[10] F. Germer, I. Zebger, M. Saggu, F. Lendzian, R. Schulz and J. Appel, "Overexpression, Isolation, and Spectroscopic Characterization of the Bidirectional [NiFe] Hydrogenase from Synechocystis sp. PCC 6803," Journal of Biological Chemistry, Vol. 284, No. 52, 2009, pp. 3646236472. http://dx.doi.org/10.1074/jbc.M109.028795

[11] L. Cournac, G. Guedeney, G. Peltier and P. M. Vignais, "Sustained Photoevolution of Molecular Hydrogen in a Mutant of Synechocystis sp. strain PCC 6803 Deficient in the Type I NADPH-Dehydrogenase Complex," Journal of Bacteriology, Vol. 186, No. 6, 2004, pp. 1737-1746. http://dx.doi.org/10.1128/JB.186.6.1737-1746.2003

[12] O. Schmitz, G. Boison, R. Hilscher, B. Hundeshagen, W. Zimmer, F. Lottspeich, and H. Bothe, "Molecular Biological Analysis of a Bidirectional Hydrogenase from Cyanobacteria," European Journal of Biochemistry, Vol. 233, No. 1, 1995, pp. 266-276. http://dx.doi.org/10.1111/j.1432-1033.1995.266 1.x

[13] J. Appel, S. Phunpruch, K. Steinmüller and R. Schulz, "The Bidirectional Hydrogenase of Synechocystis sp. PCC 6803 Works as an Electron Valve During Photosynthesis," Archives of Microbiology, Vol. 173, No. 5-6, 2000, pp. 333-338. http://dx.doi.org/10.1007/s002030000139

[14] P. Tamagnini, O. Troshina, F. Oxelfelt, R. Salema and P. Lindblad, "Hydrogenases in Nostoc sp. Strain PCC 73102, a Strain Lacking a Bidirectional Enzyme," Applied Environmental Microbiology, Vol. 63, No. 5, 1997, pp. 1801-
1807.

[15] T. Kentemich, M. Bahnweg, F. Mayer and H. Bothe, "Localization of the Reversible Hydrogenase in Cyanobacteria," Zeitschrift für Naturforschung C, A Journal of Biological Sciences, Vol. 44c, 1989, pp. 384-391.

[16] L. Serebriakova, N. A. Zorin and P. Lindblad, "Reversible Hydrogenase in Anabaena variabilis ATCC 29413: Presence and Localization in Non- $\mathrm{N}_{2}$-Fixing Cells," Archives of Microbiology, Vol. 161, No. 2, 1994, pp. 140144. http://dx.doi.org/10.1007/BF00276474

[17] K. McNeely, Y. Xu, G. Ananyev, N. Bennette, D. A. Bryant and G. C. Dismukes, "Synechococcus sp. Strain PCC 7002 nifJ Mutant Lacking Pyruvate: Ferredoxin Oxidoreductase," Applied Environmental Microbiology, Vol. 77, No. 7, 2011, pp. 2435-2444. http://dx.doi.org/10.1128/AEM.02792-10

[18] P. Tamagnini, J.-L. Costa, L. Almeida, M.-J. Oliveira, R. Salema and P. Lindblad, "Diversity of Cyanobacterial Hydrogenases, a Molecular Approach," Current Microbiology, Vol. 40, No. 6, 2000, pp. 356-361. http://dx.doi.org/10.1007/s002840010070

[19] P. M. Vignais, B. Billoud and J. Meyer, "Classification and Phylogeny of Hydrogenases," FEMS Microbiology Reviews, Vol. 25, No. 4, 2001, pp. 455-501. http://dx.doi.org/10.1016/S0168-6445(01)00063-8

[20] P. Tamagnini, R. Axelsson, P. Lindberg, F. Oxelfelt, R. Wunschiers and P. Lindblad, "Hydrogenases and Hydrogen Metabolism of Cyanobacteria," Microbiology and Molecular Biology Reviews, Vol. 66, No. 1, 2002, pp. 120. http://dx.doi.org/10.1128/MMBR.66.1.1-20.2002

[21] L. E. Mikheeva, O. Schmitz, S. V. Shestakov and H. Bothe, "Mutants of the Cyanobacterium Anabaena variabilis Altered in Hydrogenase Activities," Zeitschrift für Naturforschung C, A Journal of Biological Sciences, Vol. 50c, 1995, pp. 505-510.

[22] T. Happe, K. Schutz and H. Bohme, "Transcriptional and Mutational Analysis of the Uptake Hydrogenase of the Filamentous Cyanobacterium Anabaena variabilis ATCC 29413," Journal of Bacteriology, Vol. 182, No. 6, 2000, pp. 1624-1631. http://dx.doi.org/10.1128/JB.182.6.1624-1631.2000

[23] H. Masukawa, M. Mochimaru and H. Sakurai, "Disruption of the Uptake Hydrogenase Gene, but not of the Bidirectional Hydrogenase Gene, Leads to Enhanced Photobiological Hydrogen Production by the NitrogenFixing Cyanobacterium Anabaena sp. PCC 7120," Applied Microbiology and Biotechnology, Vol. 58, No. 5, 2002, pp. 618-624. http://dx.doi.org/10.1007/s00253-002-0934-7

[24] W. Khetkorn, P. Lindblad and A. Incharoensakdi, "Inactivation of Uptake Hydrogenase Leads to Enhanced and Sustained Hydrogen Production with High Nitrogenase Activity under High Light Exposure in the Cyanobacterium Anabaena siamensis TISTR 8012," Journal of Biological Engineering, Vol. 6, 2012, p. 19. http://dx.doi.org/10.1186/1754-1611-6-19

[25] F. Yoshino, H. Ikeda, H. Masukawa and H. Sakurai, "High Photobiological Hydrogen Production Activity of a Nostoc sp. PCC 7422 Uptake Hydrogenase-Deficient 
Mutant with High Nitrogenase Activity," Marine Biotechnology, Vol. 9, No. 1, 2007, pp. 101-112. http://dx.doi.org/10.1007/s10126-006-6035-3

[26] L. A. Sherman, H. Min, J. Toepel and H. B. Pakrasi, "Better Living Through Cyanothece-Unicellular Diazotrophic Cyanobacteria with Highly Versatile Metabolic Systems," Advances in Experimental Medicine and Biology, Vol. 675, 2010, pp. 275-90. http://dx.doi.org/10.1007/978-1-4419-1528-3 16

[27] H. Masukawa, K. Inoue and H. Sakurai, "Effects of Disruption of Homocitrate Synthase Genes on Nostoc sp. Strain PCC 7120 Photobiological Hydrogen Production and Nitrogenase," Applied and Environmental Microbiology, Vol. 73, No. 23, 2007, pp. 7562-7570. http://dx.doi.org/10.1128/AEM.01160-07

[28] H. Masukawa, K. Inoue, H. Sakurai, C. P. Wolk and R. P. Hausinger, "Site-Directed Mutagenesis of the Anabaena sp. Strain PCC 7120 Nitrogenase Active Site to Increase Photobiological Hydrogen Production," Applied and Environmental Microbiology, Vol. 76, No. 20, 2010, pp. 6741-6750. http://dx.doi.org/10.1128/AEM.01056-10

[29] C. P. Wolk, A. Ernst and J. Elhai, "Heterocyst Metabolism and Development," In: D. A. Bryant, Ed., The Molecular Biology of Cyanobacteria, Kluwer Academic Publishers, Netherlands, 1994, pp. 769-823. http://dx.doi.org/10.1007/978-94-011-0227-8_27

[30] D. A. Sveshnikov, N. V. Sveshnikova, K. K. Rao and D. O. Hall, "Hydrogen Metabolism of Mutant Forms of Anabaena variabilis in Continuous Cultures and under Nutritional Stress," FEMS Microbiology Letters, Vol. 147, No. 2, 1997, pp. 297-301.

[31] F. Yoshino, H. Ikeda, H. Masukawa and H. Sakurai, "High Photobiological Hydrogen Production Activity of Nostoc sp. PCC 7422 Uptake Hydrogenase-Deficient Mutant with High Nitrogenase Activity," Marine Biotechnology, Vol. 9, No. 1, 2007, pp.101-112. http://dx.doi.org/10.1007/s10126-006-6035-3

[32] H. Christman, E. Campbell, D. Risser, B. Phinney, W.-L. Chiu and J. C. Meeks, "Systems Level Approaches To Understanding And Manipulating Heterocyst Differentiation in Nostoc punctiforme: Sites of Hydrogenase and Nitrogenase Synthesis and Activity," Proceedings of the 2012 Department of Energy (DOE) Genomic Science Program Awardee Meeting, Bethesda, 26-29 February 2012, p. 72.

[33] J. Yu and H. Takahashi, "Biophotolysis-Based Hydrogen Production by Cyanobacteria and Green Microalgae," In: A. Méndez-Vilas, Ed., Communicating Current Research and Educational Topics and Trends in Applied Microbiology, Formatex, 2007, pp. 79-89.

[34] J. P. H. Reade, L. I. Dougherty, L. J. Rogers and J. R. Gallon, "Synthesis and Proteolytic Degradation of Nitrogenase in Cultures of the Unicellular Cyanobacterium Gloeothece Strain ATCC 27152," Microbiology, Vol. 145, No. 7, 1999, pp. 1749-1758.

http://dx.doi.org/10.1099/13500872-145-7-1749

[35] L. A. Sherman, P. Meunier, M. S. Colón-López, "Diurnal rhythms in Metabolism: A Day in The life of a Unicellular, Diazotrophic Cyanobacterium," Photosynthesis Re- search, Vol. 58, No. 1, 1998, pp. 25-42. http://dx.doi.org/10.1023/A:1006137605802

[36] A. Bandyopadhyay, J. Stockel, H. Min, L. A. Sherman and H. B. Pakrasi, "High Rates of Photobiological $\mathrm{H}_{2}$ Production by a Cyanobacterium under Aerobic Conditions," Nature Communications, Vol. 1, No. 9, 2010, p. 139. http://dx.doi.org/10.1038/ncomms1139

[37] S. Taikhao, S. Junyapoon, A. Incharoensakdi and S. Phunpruch, "Factors Affecting Biohydrogen Production by Unicellular Halotolerant Cyanobacterium aphanothece Halophytica," Journal of Applied Phycology, Vol. 25, No. 2, 2013, pp. 575-585.

[38] D. C. Ducat, G. Sachdeva and P. A. Silver, "Rewiring Hydrogenase-Dependent Redox Circuits in Cyanobacteria," Proceedings of the National Academy of Sciences of the United States of America, Vol. 108, No. 10, 2011, pp. 3941-3946. http://dx.doi.org/10.1073/pnas.1016026108

[39] P. D. Weyman, W. A. Vargas, Y. Tong, J. Yu, P.-C. Maness, H. O. Smith and Q. Xu, "Heterologous Expression of Alteromonas macleodii and Thiocapsa roseopersicina [NiFe] Hydrogenases in Synechococcus elongatus," PLoS ONE, Vol. 6, No. 5, 2011, Article ID: e20126. http://dx.doi.org/10.1371/journal.pone.0020126

[40] F. Gutthann, M. Egert, A. Marques and J. Appel, "Inhibition of Respiration and Nitrate Assimilation Enhances Photohydrogen Evolution under Low Oxygen Concentrations in Synechocystis sp. PCC 6803," Biochimica et Biophysica Acta-Bioenergetics, Vol. 1767, No. 2, 2007, pp. 161-169.

http://dx.doi.org/10.1016/j.bbabio.2006.12.003

[41] G. Ananyev, D. Carrieri and G. C. Dismukes, "Optimization of Metabolic Capacity and Flux Through Environmental Cues to Maximize Hydrogen Production by the Cyanobacterium 'Arthrospira (Spirulina) Maxima',' Applied Environmental Microbiology, Vol. 74, No. 19, 2008, pp. 6102-6113. http://dx.doi.org/10.1128/AEM.01078-08

[42] K. McNeely, Y. Xu, N. Bennette, D. A. Bryant and G. C. Dismukes, "Redirecting Reductant Flux into Hydrogen Production via Metabolic Engineering of Fermentative Carbon Metabolism in a Cyanobacterium," Applied Environmental Microbiology, Vol. 76, No. 15, 2010, pp. 5032-5038. http://dx.doi.org/10.1128/AEM.00862-10

[43] A. J. McCormick, P. Bombelli, D. J. Lea-Smith, R. W. Bradley, A. M. Scott, A. C. Fisher, A. G. Smith and C. J. Howe, "Hydrogen Production Through Oxygenic Photosynthesis Using the Cyanobacterium Synechocystis sp. PCC 6803 in a Bio-Photoelectrolysis Cell (BPE) System," Energy and Environmental Science, Vol. 6, No. 9, pp. 2682-2690. http://dx.doi.org/10.1039/c3ee40491a

[44] A. Badura, D. Guschin, T. Kothe, M. J. Kopczak, W. Schuhmann and M. Rogner, "Photocurrent Generation by Photosystem 1 Integrated in Crosslinked Redox Hydrogels," Energy and Environmental Science, Vol. 4, No. 7, 2011, pp. 2435-2440. http://dx.doi.org/10.1039/c1ee01126

[45] R. Grimme, C. E. Lubner, D. A. Bryant and J. H. Golbeck, "Photosystem I/Molecular Wire/Metal Nanoparticle Bioconjugates for the Photocatalytic Production of $\mathrm{H}_{2}$," Jour- 
nal of the American Chemical Society, Vol. 130, No. 20, 2008, pp. 6308-6309. http://dx.doi.org/10.1021/ja800923y

[46] C. E. Lubner, R. Grimme, D. A. Bryant and J. H. Golbeck, "Wiring Photosystem I for Direct Solar Hydrogen Production," Biochemistry, Vol. 49, No. 3, 2010, pp. 404-414. http://dx.doi.org/10.1021/bi901704v

[47] A. Badura, T. Kothe, W. Schuhmann and M. Rogner, "Wiring Photosynthetic Enzymes to Electrodes," Energy and Environmental Science, Vol. 4, No. 9, 2011, 32633274. http://dx.doi.org/10.1039/c1ee01285a

[48] I. Iwuchukwu, M. Vaughn, N. Myers, H. O'Neill, P. Frymier and B. D. Bruce, "Self-Organized Photosynthetic Nanoparticle for Cell-Free Hydrogen Production," Nature Nanotechnology, Vol. 5, No. 1, 2010, pp. 73-79. http://dx.doi.org/10.1038/nnano.2009.315

[49] M. Ihara, H. Nishihara, K.-S. Yoon, O. Lenz, B. Friedrich, H. Nakamoto, K. Kojima, D. Honma, T. Kamachi and I. Okura, "Light-Driven Hydrogen Production by a Hybrid Complex of a [NiFe]-Hydrogenase and the Cyanobacterial Photosystem I," Photochemistry and Photobiology, Vol. 82, No. 3, 2006, pp. 676-682. http://dx.doi.org/10.1562/2006-01-16-RA-778

[50] H. Krassen, A. Schwarze, B. Friedrich, K. Ataka, O. Lenz and J. Heberle, "Photosynthetic Hydrogen Production by a Hybrid Complex of Photosystem I and [NiFe]-Hydrogenase," ACS Nano, Vol. 3, No. 12, 2009, pp. 4055-4061. http://dx.doi.org/10.1021/nn900748j

[51] C. E. Lubner, P. Knörzer, P. J. N. Silva, K. A. Vincent, T. Happe, D. A. Bryant and J. H. Golbeck, "Wiring an
[FeFe]-Hydrogenase with Photosystem I for Light-Induced Hydrogen Production," Biochemistry, Vol. 49, No. 48, 2010, pp. 10264-10266.

[52] J. Maly, J. Krejci, M. Ilie, L. Jacubka, J. Masojidek, R. Pilloton, K, Sameh, P. Steffan, Z. Stryhal and M. Sugiura, "Monolayers of photosystem II on Gold Electrodes with Enhanced Sensor Response-Effect of Porosity and Protein Layer Arrangement," Analytical and Bioanalytical Chemistry, Vol. 381, No. 8, 2005, pp. 1558-1567. http://dx.doi.org/10.1007/s00216-005-3149-9

[53] J. Maly, J. Masojidek, A. Masci, M. Ilie, E. Cianci, V. Foglietti, W. Vastarella and R. Pilloton, "Direct Mediatorless Electron Transport Between the Monolayer of Photosystem II and Poly (Mercapto-p-Benzoquinone) Modified Gold Electrode-New Design of Biosensor for Herbicide Detection," Biosensors and Bioelectronics, Vol. 21, No. 6, 2005, pp. 923-932. http://dx.doi.org/10.1016/j.bios.2005.02.013

[54] A. Badura, B. Esper, K. Ataka, C. Grunwald, C. Wöll, J. Kuhlmann, J. Heberle and M. Rögner, "Light-Driven Water Splitting for (Bio-)Hydrogen Production: Photosystem 2 as the Central Part of a Bioelectrochemical Device," Photochemistry and Photobiology, Vol. 82, No. 5, 2006, pp. 1385-1390. http://dx.doi.org/10.1562/2006-07-14-RC-969

[55] A. Badura, D. Guschin, B. Esper, T. Kothe, S. Neugebauer, W. Schuhmann and M. Rogner, "Photo-Induced Electron Transfer Between Photosystem 2 via Crosslinked Redox Hydrogels," Electroanalysis, Vol. 20, No. 10, 2008, pp. 1043-1047. http://dx.doi.org/10.1002/elan.200804191 